Charles H. Adler, MD, $\mathrm{PhD}^{*}$

Brittany N. Dugger, PhD

Michael L. Hinni, MD

David G. Lott, MD

Erika Driver-Dunckley, MD

Jose Hidalgo

Jonette Henry-Watson

Geidy Serrano, PhD

Lucia I. Sue

Thomas Nagel, MD

Amy Duffy

Holly A. Shill, MD

Haruhiko Akiyama, $\mathrm{PhD}$

Douglas G. Walker, PhD

Thomas G. Beach, MD, $\mathrm{PhD*}$

Correspondence to

Dr. Adler:

cadler@mayo.edu

\title{
Submandibular gland needle biopsy for the diagnosis of Parkinson disease
}

\section{ABSTRACT}

Objective: This study investigates salivary gland biopsies in living patients with Parkinson disease (PD).

Methods: Patients with PD for $\geq 5$ years underwent outpatient transcutaneous needle core biopsies (18-gauge or 16-gauge) of 1 submandibular gland. Minor salivary glands were removed via a small incision in the lower lip. Tissue was fixed in formalin and serial 6- $\mu \mathrm{m}$ paraffin sections were immunohistochemically stained for phosphorylated $\alpha$-synuclein and reviewed for evidence of Lewy type $\alpha$-synucleinopathy (LTS).

Results: Fifteen patients with PD were biopsied: 9 female/6 male, mean age 68.7 years, mean PD duration 11.8 years. Twelve of the needle core biopsies had microscopically evident submandibular gland tissue to assess and 9/12 (75\%) had LTS. Only 1/15 (6.7\%) minor salivary gland biopsies were positive for LTS. Five patients had an adverse event; all were minor and transient.

Conclusions: This study demonstrates the feasibility of performing needle core biopsies of the submandibular gland in living patients with PD to assess LTS. Although this was a small study, this tissue biopsy method may be important for tissue confirmation of PD in patients being considered for invasive procedures and in research studies of other PD biomarkers. Neurology ${ }^{\circledR}$ 2014;82:858-864

\section{GLOSSARY}

$\mathbf{A D}=$ Alzheimer disease; $\mathbf{G I}=$ gastrointestinal; $\mathbf{L T S}=$ Lewy type $\alpha$-synucleinopathy; PD $=$ Parkinson disease; PNS $=$ peripheral nervous system.

There is no tissue biopsy test to diagnose Parkinson disease (PD). Many potential tissue biomarkers are being studied, including CSF, ${ }^{1-3}$ saliva, ${ }^{4}$ colon, ${ }^{5}$ and skin. ${ }^{6}$ Currently, a diagnosis is made based on clinical findings, and autopsy studies estimate the clinical diagnostic accuracy for PD ranges from $46 \%$ to $90 \% .^{7-11}$ While autopsy findings of Lewy bodies in the substantia nigra remains the gold standard for diagnosis, a postmortem survey of Lewy type $\alpha$-synucleinopathy (LTS) in the peripheral nervous system (PNS) ${ }^{12}$ found a rostral caudal gradient from the lower esophagus and submandibular gland to the colon and rectum. ${ }^{12}$ In a postmortem study of $28 \mathrm{PD}$ cases, LTS was found in all 28 whole block mounts of the submandibular gland. ${ }^{13}$ Needle cores from 17/19 (89.5\%) of these postmortem submandibular glands were positive for LTS, ${ }^{13}$ suggesting needle core biopsies in living patients with PD may be diagnostic.

As submandibular gland biopsies are used in clinical practice, usually fine-needle aspirations for cancer cell detection but also 16-gauge core needle biopsy, ${ }^{14}$ these autopsy findings led to this in vivo proof-of-concept study for submandibular gland biopsies in living patients with PD. As others have found LTS in minor salivary glands, ${ }^{15,16}$ we performed minor salivary gland biopsies as well on the same patients.

METHODS Subjects. The study was performed between August 2011 and October 2012 by the Arizona Parkinson's Disease Consortium, whose principal members are Mayo Clinic Arizona and the Banner Sun Health Research Institute. As this was a pilot

*These authors contributed equally to this work.

From the Parkinson's Disease and Movement Disorders Center (C.H.A., E.D.-D., A.D.), Department of Neurology, Mayo Clinic, Scottsdale; Banner Sun Health Research Institute (B.N.D., J.H., J.H.-W., G.S., L.I.S., H.A.S., D.G.W., T.G.B.), Sun City; the Department of Otolaryngology (M.L.H., D.G.L., T.N.), Mayo Clinic, Phoenix, AZ; and the Tokyo Institute of Psychiatry (H.A.), Tokyo, Japan.

Go to Neurology.org for full disclosures. Funding information and disclosures deemed relevant by the authors, if any, are provided at the end of the article. 
study, only 15 patients were included. Inclusion criteria included a clinical diagnosis of PD with disease duration $\geq 5$ years and a clear response to dopaminergic medication. Subjects were excluded if they were unable to sign informed consent due to dementia, had a bleeding diathesis, were taking an anticoagulant, were medically unable to undergo biopsy, or if they had a known salivary gland disorder. On the day of biopsy (both submandibular gland and minor salivary gland biopsies were performed at the same visit and the combined time took $\sim 30$ minutes) the patient met with the otolaryngologist (M.L.H., D.G.L.), who fully explained the biopsy procedures and performed the biopsies as outpatient procedures in a standard examination room.

Standard protocol approvals, registrations, and patient consents. All subjects signed written informed consent approved by the Mayo Clinic Institutional Review Board. The title of the consent form was "Salivary Gland Biopsies as a Diagnostic Test for Parkinson's Disease." Approval from the institutional review board, with a new consent form, was obtained when the biopsy needle was changed from 18-gauge to 16-gauge.

Submandibular gland biopsy. A commercially available instrument was used to obtain tissue cores (Max-Core Disposable Core Biopsy Instrument, Bard Medical, Covington, GA). Either an 18-gauge (first 4 patients) or 16-gauge needle was used. The switch to the 16-gauge needle was to increase the amount of tissue obtained during the biopsy. Both the 18- and 16-gauge needles were $10 \mathrm{~cm}$ in length, had internal diameters of 1.02 $\mathrm{mm}$ and $1.29 \mathrm{~mm}$, and a sample notch of $1.8 \mathrm{~cm}$ and $1.9 \mathrm{~cm}$, respectively.

Submandibular glands were localized by palpation and biopsies were performed unilaterally (figure 1$)$. Local anesthetic $(0.5 \mathrm{~mL}$ of lidocaine) was injected into the skin overlying the submandibular gland. This was followed by a 3 - to 5 -minute waiting period to allow the lidocaine to take effect. The biopsy needle was inserted transcutaneously, parallel (first 4 cases) then perpendicular to the longitudinal axis of the gland, to a depth of $\sim 22 \mathrm{~mm}$. Between 1 and 5 needle core biopsies were performed for each patient. After the procedure, pressure was used briefly to stop bleeding.

Minor salivary gland biopsy. The minor salivary gland biopsies were performed by everting the lower lip and injecting local anesthetic $(0.5 \mathrm{~mL}$ lidocaine) subcutaneously into the medial aspect a few millimeters below the upper aspect of the lower lip. A few minutes were given for the drug to take effect. A

\section{Figure 1 Needle biopsy of the submandibular gland}

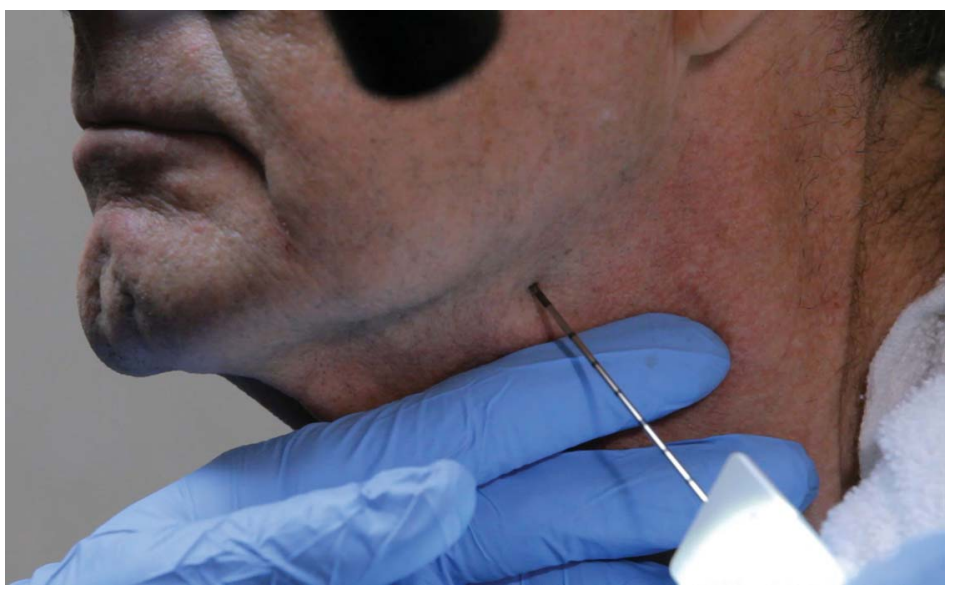

2- to 3 -mm vertical incision was then made in the lip through which between 2 and 5 minor salivary glands were obtained. Minor salivary glands were individually removed and required dissection away from adjoining tissue using forceps and a scissors. One to three dissolvable sutures were used to close the incision site.

The day after the procedure, each patient was contacted by telephone to inquire about adverse events.

Tissue preparation. Tissue from submandibular gland and minor salivary glands were immediately placed in separate single standard plastic cassettes between 2 sponges and immersed in $70 \mathrm{~mL}$ of neutral-buffered $10 \%$ formalin (Fisher Scientific, Kalamazoo, MI). After 24 hours fixation at $4^{\circ} \mathrm{C}$, the tissue cores were dehydrated in alcohols, infiltrated with paraffin, and serial sections cut at 5-7 $\mu \mathrm{m}$ with a rotary microtome. Every section was collected and mounted on a separate slide, beginning with the first appearance of tissue fragments and ending when tissue fragments were no longer visible. Reserving half of the sections in case of possible technical failure, every second section was immunohistochemically stained for phosphorylated $\alpha$-synuclein using an immunoperoxidase reaction with nickel enhancement followed by a light Neutral Red counterstain. ${ }^{13}$ The prior evaluation of several different immunohistochemical methods has been published previously. ${ }^{17}$ Proteinase $\mathrm{K}$ was found to give not only superior epitope exposure but also may assist with stain specificity by digesting normal, non-aggregated $\alpha$-synuclein, which has been a confounding factor in some recent studies. ${ }^{18,19}$ The primary antibody was raised against $\alpha$-synuclein phosphorylated at serine $129^{20}$ and has been demonstrated to be reactive only with the phosphorylated epitope ${ }^{21}$; this makes it more likely that stained peripheral structures are pathologic, as we have found that normal control subjects never have immunohistochemically positive PNS elements. ${ }^{12}$ Adjustment of the original protocol to better suit peripheral tissue and needle cores has been described in detail. ${ }^{13}$

RESULTS Fifteen patients with PD were enrolled: 9 female and 6 male, mean age was 68.7 years (range 61-81), and the mean PD disease duration was 11.8 years (range 6-17). Thirteen patients had motor fluctuations. Six were former smokers, having quit at least 15 years prior to the biopsy.

Submandibular gland biopsy findings. Submandibular gland tissue core total length and total tissue volume varied (table). Total core length and total core volume markedly increased when the biopsy method changed to perpendicular rather than parallel needle insertions, more needle insertions, and a larger caliber needle (16-gauge vs 18-gauge).

Initial microscopic examination of the submandibular gland tissue cores showed the variable presence of skin, subcutaneous tissue, striated muscle, and salivary gland tissue. Three of the initial cases did not have any tissue elements consistent with submandibular gland and others had miniscule amounts, $<1.6 \mathrm{~mm}^{2}$ on greatest cross-sectional area, so the sampling method was expanded (as described above), resulting in a total of 12 cases having identifiable salivary gland tissue. Microscopic assessment for LTS revealed 9 of 12 subjects $(75 \%)$ with identifiable salivary gland were positive. A characteristic needle core tissue sample is 


\begin{tabular}{|c|c|c|c|c|c|c|c|}
\hline \multirow{2}{*}{$\begin{array}{l}\text { Table } \\
\text { Subject }\end{array}$} & \multicolumn{7}{|c|}{ Details of results for submandibular needle cores } \\
\hline & Gauge & Core length, $\mathrm{mm}$ & Tissue volume, $\mathrm{mm}^{3}$ & Max gland area, $\mathrm{mm}^{2}$ & Positive stained slides & Total slides & $\%$ Positive stained slides \\
\hline 1 & 18 & 9 & 7.3 & 0.0 & 0 & 48 & 0 \\
\hline 2 & 18 & 10 & 8.2 & 1.6 & 0 & 57 & 0 \\
\hline 3 & 18 & 10 & 8.2 & 1.1 & 2 & 75 & 3 \\
\hline 4 & 18 & 9 & 7.3 & 0.0 & 0 & 53 & 0 \\
\hline 5 & 16 & 10 & 13.1 & 0.0 & 0 & 58 & 0 \\
\hline 6 & 16 & 11 & 14.4 & 2.0 & 14 & 58 & 20 \\
\hline 7 & 16 & 11 & 14.4 & 1.4 & 0 & 63 & 0 \\
\hline 8 & 16 & 15 & 19.6 & 0.2 & 4 & 105 & 4 \\
\hline 9 & 16 & 19 & 24.8 & 2.4 & 5 & 92 & 5 \\
\hline 10 & 16 & 14 & 18.3 & 3.2 & 0 & 40 & 0 \\
\hline 11 & 16 & 26 & 34.0 & 9.8 & 30 & 70 & 43 \\
\hline 12 & 16 & 13.5 & 17.6 & 0.9 & 34 & 78 & 44 \\
\hline 13 & 16 & 14 & 18.3 & 6.0 & 6 & 57 & 11 \\
\hline 14 & 16 & 11 & 14.4 & 1.3 & 8 & 33 & 24 \\
\hline 15 & 16 & 24 & 31.4 & 8.1 & 30 & 51 & 60 \\
\hline
\end{tabular}

Tissue volume $\left(\mathrm{mm}^{3}\right)$ was calculated using the formula for volume of a cylinder. The total core tissue length (mm) was used as cylinder height while cylinder radius was calculated from the internal diameter of the needle, as supplied by the manufacturer. The maximum total $\mathrm{cross}^{-s^{2}} \mathrm{ctional}^{2}$ area $\left(\mathrm{mm}^{2}\right)$ of microscopically identified submandibular gland area was measured using an ocular graticule under the microscope. The number of positive slides is the number that had positive phosphorylated $\alpha$-synuclein-immunoreactive nerve elements present. Total slides is the total number of microscope slides stained and examined. The last column is the percentage of slides that were positive for phosphorylated $\alpha$-synuclein-immunoreactive nerve elements.

presented (figure 2A). Only structures morphologically consistent with nervous tissue were considered to represent a positive biopsy finding (figure 2). Eight of the 9 positive cases had immunoreactive phosphorylated $\alpha$-synuclein staining in nerve fibers or puncta within submandibular salivary gland tissue while 1 was positive only in the subcutaneous connective tissue of a skin fragment. Positive fibers were most frequently seen within stromal connective tissue of the gland, often within nerve fascicles (figure 2, B and C) but also close to or within the walls of small arteries and arterioles (figure 2D) or just beneath duct epithelium (figure 2E). Less commonly but not infrequently, immunoreactive fibers were seen interweaving among parenchymal serous gland cells (figure $2 \mathrm{~F}$ ). Up to 105 stained submandibular gland sections were examined for each subject with a mean positive slide percentage of $23.7 \%$ (table). There were no clinically distinguishable features among the 3 subjects that had negative biopsies.

Nonspecific staining (staining that was not in nervous tissue) was present in occasional tissue fragments, including staining of keratinizing cells or material within hair follicles of skin (figure 2G) and staining of the edges of striated muscle fibers (figure $2 \mathrm{H}$ ). Similar to the previously published results for autopsied submandibular gland, ${ }^{13}$ serous cell cytoplasmic staining was also observed in some cases and was considered to be nonspecific.

Minor salivary gland biopsy findings. All the minor salivary gland tissue fragments had relatively large amounts of glandular tissue present, as well as connective tissue. Total tissue volume ranged between 10 and $180 \mathrm{~mm}^{3}$ and $21-106$ stained slides were examined per subject. Only $1 / 15$ cases had immunoreactive nerve fibers seen within both stroma and parenchyma (not shown). This subject was one of the subjects who had a positive submandibular gland biopsy.

Side effects. Side effects were minimal, with 5 patients having 1 adverse event each: swollen cheek, sore throat, excess fluid expelled from the needle biopsy site after a sneeze, swelling under the chin, and slight bleeding/swelling/bruising under the jaw.

DISCUSSION A tissue biopsy diagnostic test for PD could improve our current ability to treat patients and revolutionize how we perform and validate research studies for PD. To address the issue of an optimal peripheral biopsy site for PD, an extensive survey for LTS in the PNS of 41 tissue sites was performed. ${ }^{12}$ As in previous studies, ${ }^{22}$ the gastrointestinal (GI) tract contained LTS in most subjects with PD and there was a rostrocaudal gradient of GI LTS density, with the lower esophagus and submandibular gland having the highest densities and the colon and rectum the lowest. ${ }^{12,16,23,24}$ Prior to performing biopsies in living patients with PD, a postmortem submandibular gland study of 92 subjects with and without PD was performed. ${ }^{13}$ Using immunohistochemical staining for phosphorylated $\alpha$-synuclein, ${ }^{17,25}$ both large blocks 

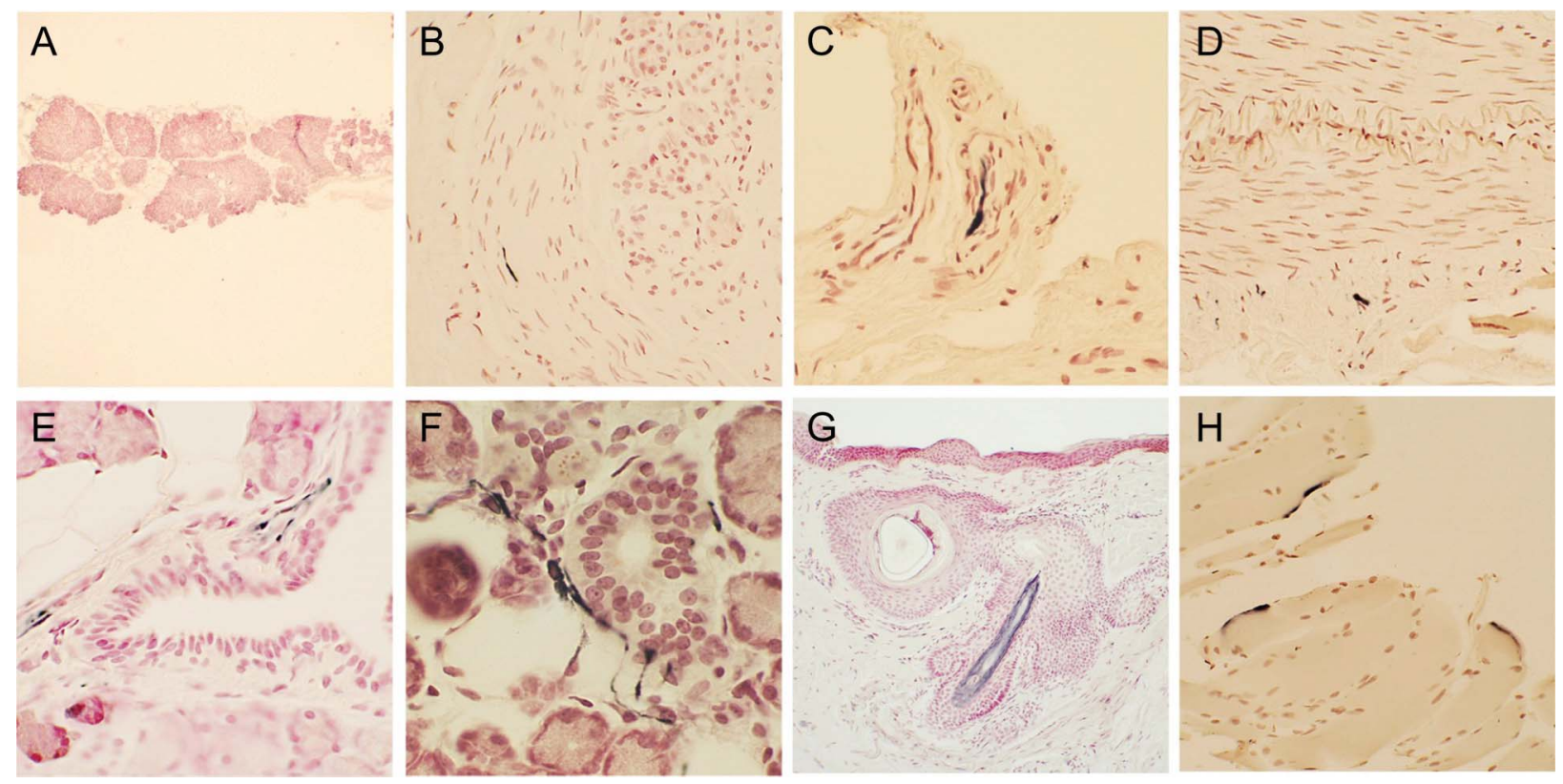

Sections were stained with an immunohistochemical method for phosphorylated $\alpha$-synuclein (see Methods). Only structures immunoreactive for phosphorylated $\alpha$-synuclein (black) and morphologically consistent with nervous tissue were considered to represent a positive biopsy finding. Sections were counterstained with Neutral Red. (A) Typical needle core tissue sample. (B) Single immunoreactive nerve fiber within a nerve fascicle running in connective tissue stroma adjacent to glandular parenchyma. (C) Single immunoreactive nerve fiber within a stromal nerve fascicle. (D) Immunoreactive puncta within the adventitia of a small artery in the stroma. (E) Several immunoreactive nerve fibers running beneath duct epithelium. (F) Immunoreactive nerve fibers interweaving among parenchymal serous gland cells. (G) Nonspecific staining (black) of hair follicle within a fragment of skin. (H) Nonspecific staining (black) of the edges of muscle fibers.

(simulated open biopsy) and needle cores (simulated needle core biopsy) were assessed for LTS. The results showed high sensitivity (LTS in 28/28 PD cases) and specificity (only $3 / 22$ patients with Alzheimer disease $[\mathrm{AD}]$ with Lewy bodies had submandibular gland LTS, while there was no positive staining in 5 subjects with incidental Lewy body disease, 2 with progressive supranuclear palsy, 3 with corticobasal degeneration, 2 with multiple system atrophy, 16 patients with $\mathrm{AD}$ without Lewy bodies, and 50 elderly control subjects). The next step in proof-of-concept for in vivo biopsies was a needle core biopsy of 19 of the postmortem PD submandibular glands, which found 17/19 (89.5\%) were positive for LTS. Whereas this is a high positive rate, it also showed that needle core biopsies will miss some cases. ${ }^{13}$

The present study was the first in vivo submandibular gland biopsy study and found LTS in 9 of 12 subjects with PD. If we assume, using published studies, ${ }^{7-11}$ a clinical diagnostic accuracy rate (positive predictive value) of $85 \%$, then $0.85 \times 12=10$ subjects in the present study would be likely to have autopsy-confirmed $\mathrm{PD}$, suggesting our finding of 9/12 positive biopsies has high sensitivity. Additionally, as the postmortem needle biopsies of submandibular glands missed affected tissue ${ }^{13}$ the lack of $100 \%$ positivity is not surprising. While specificity was not assessed in this study as no control subjects or subjects with other parkinsonian disorders were included, results from Beach et al..$^{13}$ suggest that specificity for PD would be very high.

The initial difficulty with obtaining sufficient glandular tissue was largely rectified by using a larger caliber needle (16-gauge instead of 18-gauge), changing the trajectory of the needle insertion so that it was perpendicular to the gland's longitudinal axis, and taking more cores (4-5 instead of 1-2). Only 1 case out of $11 \mathrm{had}$ no glandular tissue after the procedure was modified. Despite this success, ultrasound-guided biopsies may be considered in the future rather than just identifying the submandibular gland by palpation. At the present time, the amount of tissue sample needed to adequately find LTS is unclear, but the data suggest that at least $2 \mathrm{~mm}^{2}$ on greatest cross-sectional area, or $8 \mathrm{~mm}^{3}$ volumetrically, of microscopically identifiable salivary gland be used as a provisional definition.

In contrast to the submandibular gland biopsy results, the minor salivary gland biopsy was not sensitive for finding LTS, despite that fact that there was much more glandular tissue studied from the open minor salivary gland biopsies than from the submandibular gland needle cores. Although it was previously reported that $2 / 3$ subjects with $P D$ had positive LTS in minor salivary gland biopsies, ${ }^{16}$ we found that only $1 / 15$ cases were positive. This case also had a positive submandibular gland biopsy. After we had completed our study, another published study 
reported rare $(3 / 16 \mathrm{PD}$ cases with disease duration $>8$ years) LTS in minor salivary gland biopsies. ${ }^{15}$ Weak positive staining was also found in 2 nonparkinsonian neurologic disease controls. ${ }^{15}$ It is unclear why submandibular and minor salivary gland biopsy results differ. The parasympathetic innervation to both the submandibular gland and the labial minor salivary glands come from the lingual nerve, so this would not appear to be the cause. There are no published investigations of minor salivary gland tissue in autopsied PD cases so the presence of LTS in the minor salivary glands may not be a finding in PD. ${ }^{15}$ Further use of minor salivary gland biopsies in PD is likely not warranted.

Another possible GI biopsy site is the colon. ${ }^{26}$ Recent studies ${ }^{5,27-30}$ have shown this is feasible but most of these studies required significant preprocedure preparation, sedation, general anesthesia, and more resources than the submandibular gland biopsy. ${ }^{13,27,28}$ There also are conflicting data regarding the density of LTS in the submucosa of the colon as opposed to the myenteric plexus, and whether deeper layer biopsy into the muscular layer of the colon would be needed, which would increase risk to the patient and may be difficult to perform via a colonoscopy. ${ }^{5,22,31,32}$ A more recent study of unprepped

\section{Comment:}

\section{Braak staging in clinical practice?}

The longitudinal assessment of the neuropathology of Parkinson disease by the use of the molecular marker $\alpha$-synuclein (Braak staging) has shown that the disease has a peripheral component; moreover, according to convincing studies by Braak et al., ${ }^{1}$ it is even likely that the disease originates in the periphery, outside the CNS. This change in paradigm has initiated a search for peripheral biomarkers for the disease fueled by hopes that an early diagnosis will finally lead to prevention ${ }^{2}$-once we can therapeutically interfere with the spreading of the disease. The article by Adler et al. ${ }^{3}$ describes in a proof-of-principle approach that the examination of nerve fibers of the submandibular salivary glands is a feasible and sensible way to reach this goal. The authors also refined the technical approach to the biopsy. Although they succeeded in detecting $\alpha$-synuclein in 9/15 patients, further technical refinement might improve the sensitivity of the procedure to the point of routine clinical utility. Whether this technique could then be used to provide a preclinical biomarker will require further validation.

According to the studies of the Braaks, it would be interesting to investigate patients with early rather than late disease. The findings of Adler et al. demonstrated that the exciting prospect of finding a systemic and potentially preclinical biomarker for Parkinson disease is feasible.

1. Braak H, Del Tredici K, Rüb U, de Vos RAI, Jansen Steur ENH, Braak E. Staging of brain pathology related to sporadic Parkinson's disease. Neurobiol Aging 2003;24: 197-210.

2. Del Tredici K, Hawkes $\mathrm{CH}$, Ghebremedhin E, Braak H. Lewy pathology in the submandibular gland of individuals with incidental Lewy body disease and sporadic Parkinson's disease. Acta Neuropathol 2010;119:703-713.

3. Adler CH, Dugger BN, Hinni ML, et al. Submandibular gland needle biopsy for the diagnosis of Parkinson disease. Neurology 2014;82:858-864.

\section{Albert C. Ludolph, MD}

From the Department of Neurology, University of Ulm, Germany.

Study funding: No targeted funding reported.

Disclosure: The author reports no disclosures relevant to the manuscript. Go to Neurology.org for full disclosures. flexible sigmoidoscopy is promising as an accessible site for outpatient tissue biopsy. ${ }^{5}$ This study did not use phosphorylated $\alpha$-synuclein and while staining was only found in PD cases and not in controls, further study is needed. ${ }^{5}$ One clinical study and multiple autopsy studies suggest rectal biopsy would not be of value. ${ }^{12,22,23,29,31,33}$ The skin has also been investigated as a biomarker for PD; however, multiple studies have found minimal LTS in the skin. ${ }^{6,12}$

Other areas of biomarker development include assessing proteins in the CSF and saliva. However, no clear biomarker has been found. ${ }^{1,2,4,34,35}$ Noninvasive biomarkers, while sensitive, do not have high enough specificity to be diagnostic. ${ }^{36,37}$

One limitation of this study was the selection of PD cases with disease duration of $\geq 5$ years and responsiveness to dopaminergic medications (13 of the 15 cases had motor fluctuations). These selection criteria were used as they provided similar patient characteristics to the autopsy study ${ }^{13}$ and this was to provide proof-ofconcept. It is clear that accuracy of the clinical diagnosis of PD improves in more advanced disease. ${ }^{7-11}$ Depending on the criteria used for the diagnosis, many cases may not have a striatal dopaminergic deficit and many will have non-PD parkinsonism due to other neurodegenerative disorders such as progressive supranuclear palsy, multiple system atrophy, and corticobasal degeneration. Given the results in this study, future studies with patients with shorter disease duration will be important as having an accurate tissue diagnosis in patients with early PD would greatly increase the probability for successful clinical trials and provide tissue confirmation for other biomarker studies. In patients with more advanced PD, tissue confirmation by submandibular gland biopsy may be of potential use for selecting subjects for high-risk interventions such as deep brain stimulation, cell transplantation, and gene therapy. Additionally, tissue confirmation in patients with advanced PD would be valuable for other biomarker studies (genetic, CSF, saliva) that currently lack autopsy confirmation. An accurate tissue diagnosis for living patients with PD would therefore be of great benefit as a gold standard for confirming other biomarkers.

Another limitation of this study was the lack of control subjects. However, based on the autopsy study, ${ }^{13}$ there was no evidence of LTS in 50 control subjects. This study also did not include subjects with other parkinsonian disorders, so determination of the specificity for LTS in submandibular gland biopsies for PD will require further study.

This study does provide proof-of-concept evidence for the feasibility of using submandibular gland biopsy as a sensitive tissue-based diagnostic test for the presence of LTS in living patients with clinically diagnosed PD. Submandibular gland biopsies were performed as outpatient procedures, used only local anesthetic, and 
were well-tolerated. Combined with the autopsy study, ${ }^{13}$ the results suggest that submandibular gland biopsy may be a sensitive outpatient method to obtain tissue confirmation of LTS in PD. Future studies should include patients with early-stage PD, control subjects, subjects with other parkinsonian disorders, and, when possible, longitudinal studies extended to autopsy with neuropathologic confirmation of PD.

\section{AUTHOR CONTRIBUTIONS}

All authors contributed to manuscript writing/revision. Authors involved in patient recruitment and clinical activities included C. Adler, M. Hinni, D. Lott, E. Driver-Dunckley, A. Duffy, H. Shill, and T. Nagel, while authors involved in postbiopsy tissue analysis included B. Dugger, J. Hidalgo, J. Henry-Watson, G. Serrano, L. Sue, H. Akiyama, D. Walker, and T. Beach.

\section{ACKNOWLEDGMENT}

The authors thank the patients who were willing to undergo biopsies for this study. Other members of the Arizona Parkinson's Disease Consortium who were helpful in discussions include John Caviness, MD, Marwan Sabbagh, MD, Sandra Jacobson, MD, Christi Belden, PhD, Joseph Hentz, MS, and Kathryn Davis. The authors also thank J. William Langston, MD, for support and discussions.

\section{STUDY FUNDING}

Funded by the Michael J. Fox Foundation for Parkinson's Research. Support for the Arizona Parkinson's Disease Consortium was also provided by the National Institute of Neurological Disorders and Stroke (U24 NS072026 National Brain and Tissue Resource for Parkinson's Disease and Related Disorders)

\section{DISCLOSURE}

The authors report no disclosures relevant to the manuscript. Go to Neurology.org for full disclosures.

Received June 24, 2013. Accepted in final form November 15, 2013

\section{REFERENCES}

1. Maarouf CL, Beach TG, Adler CH, et al. Cerebrospinal fluid biomarkers of neuropathologically diagnosed Parkinson's disease subjects. Neurol Res 2012;34:669_ 676.

2. Hong Z, Shi M, Chung KA, et al. DJ-1 and alphasynuclein in human cerebrospinal fluid as biomarkers of Parkinson's disease. Brain 2010;133:713-726.

3. Shi M, Furay AR, Sossi V, et al. DJ-1 and alphaSYN in LRRK2 CSF do not correlate with striatal dopaminergic function. Neurobiol Aging 2012;33:836.e835837.

4. Devic I, Hwang HJ, Edgar JS, et al. Salivary alphasynuclein and DJ-1: potential biomarkers for Parkinson's disease. Brain 2011;134.

5. Shannon KM, Keshavarzian A, Mutlu E, et al. Alphasynuclein in colonic submucosa in early untreated Parkinson's disease. Mov Disord 2012;27:709-715.

6. Miki Y, Tomiyama M, Ueno $\mathrm{T}$, et al. Clinical availability of skin biopsy in the diagnosis of Parkinson's disease. Neurosci Lett 2010;469:357-359.

7. Caslake R, Moore JN, Gordon JC, Harris CE, Counsell C. Changes in diagnosis with follow-up in an incident cohort of patients with parkinsonism. J Neurol Neurosurg Psychiatry 2008;79:1202-1207.

8. Hughes AJ, Daniel SE, Kilford L, Lees AJ. The accuracy of the clinical diagnosis of Parkinson's disease: a clinicopathological study of 100 cases. J Neurol Neurosurg Psychiatry 1992;55:181-184.
9. Hughes AJ, Daniel SE, Lees AJ. Improved accuracy of clinical diagnosis of Lewy body Parkinson's disease. Neurology 2001;57:1497-1499.

10. Gelb DJ, Oliver E, Gilman S. Diagnostic criteria for Parkinson disease. Arch Neurol 1999;56:33-39.

11. Gibb WR. Neuropathology of Parkinson's disease and related syndromes. Neurol Clin 1992;10:361-376.

12. Beach TG, Adler CH, Sue LI, et al. Multi-organ distribution of phosphorylated alpha-synuclein histopathology in subjects with Lewy body disorders. Acta Neuropathol 2010;119:689-702.

13. Beach TG, Adler CH, Dugger BN, et al. Submandibular gland biopsy for the diagnosis of Parkinson's disease. J Neuropathol Exp Psychiatry 2013;72:130-136.

14. Bahn YE, Lee SK, Kwon SY, Kim SP. Sonographic appearances of mucosa-associated lymphoid tissue lymphoma of the submandibular gland confirmed with sonographically guided core needle biopsy. J Clin Ultrasound 2011;39:228-232.

15. Folgoas E, Lebouvier T, Leclair-Visonneau L, et al. Diagnostic value of minor salivary glands biopsy for the detection of Lewy pathology. Neurosci Lett 2013;551:62-64.

16. Cersosimo MG, Perandones C, Micheli FE, et al. Alphasynuclein immunoreactivity in minor salivary gland biopsies of Parkinson's disease patients. Mov Disord 2011;26: 188-190.

17. Beach TG, White CL, Hamilton RL, et al. Evaluation of alpha-synuclein immunohistochemical methods used by invited experts. Acta Neuropathol 2008;116:277-288.

18. Minguez-Castellanos A, Chamorro CE, Escamilla-Sevilla F, et al. Do alpha-synuclein aggregates in autonomic plexuses predate Lewy body disorders? A cohort study. Neurology 2007;68:2012-2018.

19. Oinas M, Paetau A, Myllykangas L, Notkola IL, Kalimo H, Polvikoski T. Alpha-synuclein pathology in the spinal cord autonomic nuclei associates with alphasynuclein pathology in the brain: a population-based Vantaa 85+ study. Acta Neuropathol 2010;119:715-722.

20. Fujiwara H, Hasegawa M, Dohmae N, et al. Alpha-synuclein is phosphorylated in synucleinopathy lesions. Nat Cell Biol 2002;4:160-164.

21. Walker DG, Lue LF, Adler CH, et al. Changes in properties of serine 129 phosphorylated alpha-synuclein with progression of Lewy-type histopathology in human brains. Exp Neurol 2013;240:190-204.

22. Wakabayashi K, Takahashi H, Takeda S, Ohama E, Ikuta F. Parkinson's disease: the presence of Lewy bodies in Auerbach's and Meissner's plexuses. Acta Neuropathol 1988;76:217-221.

23. Wakabayashi K, Takahashi H, Ohama E, Ikuta F. Parkinson's disease: an immunohistochemical study of Lewy bodycontaining neurons in the enteric nervous system. Acta Neuropathol 1990;79:581-583.

24. Del Tredici K, Hawkes $\mathrm{CH}$, Ghebremedhin E, Braak H. Lewy pathology in the submandibular gland of individuals with incidental Lewy body disease and sporadic Parkinson's disease. Acta Neuropathol 2010;119:703-713.

25. Beach TG, Adler CH, Lue L, et al. Unified staging system for Lewy body disorders: correlation with nigrostriatal degeneration, cognitive impairment and motor dysfunction. Acta Neuropathol 2009;117:613-634.

26. Braak H, de Vos RA, Bohl J, Del Tredici K. Gastric alphasynuclein immunoreactive inclusions in Meissner's and Auerbach's plexuses in cases staged for Parkinson's diseaserelated brain pathology. Neurosci Lett 2006;396:67-72. 
27. Shannon KM, Keshavarzian A, Dodiya HB, Jakate S, Kordower JH. Is alpha-synuclein in the colon a biomarker for premotor Parkinson's disease? Evidence from 3 cases. Mov Disord 2012;27:717-719.

28. Lebouvier T, Neunlist M, Bruley des Varannes $S$, et al. Colonic biopsies to assess the neuropathology of Parkinson's disease and its relationship with symptoms. PLoS One 2010;5:e12728.

29. Lebouvier T, Chaumette T, Damier P, et al. Pathological lesions in colonic biopsies during Parkinson's disease. Gut 2008;57:1741-1743.

30. Pouclet H, Lebouvier T, Coron E, Des Varannes SB, Neunlist M, Derkinderen P. A comparison between colonic submucosa and mucosa to detect Lewy pathology in Parkinson's disease. Neurogastroenterol Motil 2012;24: e202-205.

31. Annerino DM, Arshad S, Taylor GM, Adler $\mathrm{CH}$, Beach TG, Greene JG. Parkinson's disease is not associated with gastrointestinal myenteric ganglion neuron loss. Acta Neuropathol 2012;124:665-680.
32. Wakabayashi K, Takahashi H, Takeda S, Ohama E, Ikuta F. Lewy bodies in the enteric nervous system in Parkinson's disease. Arch Histol Cytol 1989;52 suppl: 191-194.

33. Pouclet $\mathrm{H}$, Lebouvier $\mathrm{T}$, Coron $\mathrm{E}$, et al. A comparison between rectal and colonic biopsies to detect Lewy pathology in Parkinson's disease. Neurobiol Dis 2012;45:305-309.

34. LeWitt P. Recent advances in CSF biomarkers for Parkinson's disease. Parkinsonism Relat Disord 2012; 18(suppl 1):S49-S51.

35. Hall S, Ohrfelt A, Constantinescu R, et al. Accuracy of a panel of 5 cerebrospinal fluid biomarkers in the differential diagnosis of patients with dementia and/or parkinsonian disorders. Arch Neurol 2012;69:1445-1452.

36. Vlaar AM, de Nijs T, Kessels AG, et al. Diagnostic value of 123I-ioflupane and 123I-iodobenzamide SPECT scans in 248 patients with parkinsonian syndromes. Eur Neurol 2008;59:258-266.

37. Berg D, Godau J, Walter U. Transcranial sonography in movement disorders. Lancet Neurol 2008;7:1044-1055.

\section{This Week's Neurology ${ }^{\circledR}$ Podcast}

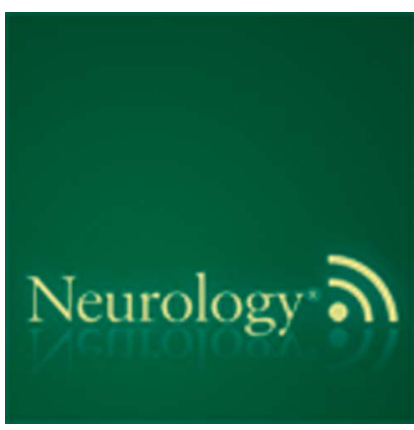

Submandibular gland needle biopsy for the diagnosis of Parkinson disease

This podcast begins and closes with Dr. Robert Gross, Editor-inChief, briefly discussing highlighted articles from the March 11, 2014, issue of Neurology. In the second segment, Dr. Michelle Brown talks with Dr. Charles Adler about submandibular gland needle biopsy for diagnosis of Parkinson disease. Dr. Roy Strowd reads our e-Pearl of the week about nodes needing neurofascin. In the next part of the podcast, Dr. Maria Farrugia focuses her interview with Dr. Andrew Schaefer on syndromes of mitochondrial disorders. Disclosures can be found at www.neurology.org.

At www.neurology.org, click on "RSS" in the Neurology Podcast box to listen to the most recent podcast and subscribe to the RSS feed.

CME Opportunity: Listen to this week's Neurology Podcast and earn 0.5 AMA PRA Category

1 CME Credits ${ }^{\mathrm{TM}}$ by answering the multiple-choice questions in the online Podcast quiz.

\section{Get Connected. Stay Connected.}

Connect with the American Academy of Neurology's popular social media channels to stay up-todate on the latest news and breakthroughs in neurology, and network with peers and neurology thought leaders. Visit $A A N$.com/Connect. 